\title{
Palliative Care in a COVID-19 Intensive Care Unit (ICU): Challenges and Recommendations for Palliative Care Teams in a Pandemic ICU
}

\section{Dear Editor,}

A growing number of countries are facing the ominous prospect of their healthcare infrastructure being overwhelmed by the COVID-19 pandemic. ${ }^{1}$ As of 20 June 2020, Singapore has a total of 41,615 infections and 26 deaths. ${ }^{2-3}$

Although the World Health Organization (WHO) reports the average death rate from COVID-19 to be between $2-4 \%$, case-fatality rate in elderly patients is estimated to be about $8.0-14.8 \% .^{4-5}$ This figure will rise even more acutely when intensive care units (ICUs) become overwhelmed by surging caseloads. ${ }^{1}$ It is therefore important that palliative care teams are integrated into the COVID-ICUs. ${ }^{6-7}$ Fausto et al shared how their centre developed multifaceted strategies for palliative care to be incorporated into areas like the emergency department, ICUs and acute care services to help address goals of care, symptoms management and support family members. ${ }^{8}$ We add to this rapidly evolving literature by focusing on how our hospital developed an ICU-Palliative Care collaborative strategy in a COVID-19 designated ICU.

Our hospital is a 1500-bed university teaching hospital co-located with the National Centre of Infectious Diseases (NCID) which currently manages the majority of COVID-19 patients in Singapore. The NCID is a 330-bed purpose-built facility with 36 ICU beds designed to strengthen Singapore's capabilities in handling outbreaks of infectious diseases. ${ }^{9}$

We have a dedicated Palliative Care ICU-Service which serves all the ICUs in the hospital. In anticipation of the increasing number of critically ill patients who may require palliative care, the ICU directors and Palliative Care leadership had agreed to foster closer collaboration between our specialties. We share our recommendations of this collaboration in the context of a COVID-19 designated ICU in Singapore.

We present a case of a COVID-19 patient, highlighting the challenges faced by patients and their families and make recommendations for the integration of palliative care and its principles into a COVID-19 ICU.

\section{Case Vignette 1}

Mr L was a socially active 80-year old gentleman with hypertension. He tested positive for COVID-19 and developed respiratory failure and acute respiratory distress syndrome (ARDS) on day 8 of illness. He was intubated and prone ventilated, but continued to deteriorate despite a trial of lopinavir/ritonavir and interferon. Peripheral vasoconstriction secondary to inotropic use resulted in digital gangrene of all four limbs.

He was heavily sedated, precluding any meaningful conversations. The Palliative Care team was referred and conducted a family meeting with the ICU team to establish goals of care. His family members were certain $\mathrm{Mr} \mathrm{L}$ would not have wanted further aggressive interventions and that his current physical state was not compatible with his own views of life and dignity. His inotropes were not further escalated and he died the following day with three family members beside him. He had tested negative for COVID-19 by then but his family was gowned up in full personal protective equipment (PPE) as a precaution. A favourite grandson who had been exposed to COVID-19 could not be present as he was being quarantined. Mr L's body was 'double-bagged' in strict compliance with infection control protocols. A funeral service was not conducted as his family did not expect relatives to come to the funeral. He was cremated the day after his death.

Integrating Palliative Care into a COVID-19 ICU: How We Did It.

Pre-emptive Screening of COVID-19 Patients using an ICU-Palliative Care Referral Checklist

It is imperative that palliative care teams actively engage their ICU colleagues in a timely manner to identify patients in the COVID-19 ICU who may 
benefit from an early palliative care referral. Our ICU-Palliative Care team screens all the COVID-19 positive critically ill patients regularly to promptly identify patients with unmet palliative care needs.

Our current ICU-Palliative Care checklist (Table 1) was formalised in 2015 when the hospital first set up its ICU-Palliative Care Service. These 'triggers' were adapted from the IPAL-ICU recommendations and relevant literature. ${ }^{10-12}$ Important criteria which may be most relevant for COVID-19 patients are: (1) status post cardiopulmonary arrest, (2) multiorgan dysfunction involving $\geq 2$ organ systems, (3) consideration of mechanical ventilator withdrawal with death expected. Our patient fulfilled the criteria for both points 2 and 3 .

\section{Regular Combined Palliative Care and ICU Meetings}

As more COVID-19 patients entered the ICU, the ICU teams valued regular input from the Palliative Care team and these combined meetings increased from weekly to 2-3 times per week with daily ad hoc discussions of patients' progress. Mr L was brought to the attention of the Palliative Care team in one of these multi-disciplinary team meetings. Having joint meetings on a daily to weekly basis depending on patient load helped identify patients with (1) high likelihood of treatment failure, (2) worsening multiorgan failure or (3) complications of treatment. This ensured that all members of the COVID ICU team were aligned to the prognosis and treatment goals which helped better engage distressed families.

\section{Early Engagement of Families}

Palliative care teams play an important role in early engagement of families for goals of care discussions when the anticipated prognosis of ICU patients is poor, particularly in the frail, elderly patient population with the multiple co-morbidities.

\section{Process of Withdrawal of Mechanical Ventilation}

As a joint unit, the Palliative Care team, in collaboration with the ICU team can discuss withdrawal of ventilation in patients with a poor prognosis and educate family about the illness trajectory following extubation. We can also provide an independent opinion to the ICU team in equivocal cases regarding the timing and decision of withdrawal. This can be perceived as valuable support and a show of solidarity to our fellow healthcare providers who are facing an overwhelmingly high mortality in the COVID-19 ICUs.

To better prepare and manage the symptoms following terminal withdrawal of mechanical ventilatory support, a workflow detailing the process of preparing the patients, their families and the medical teams for terminal extubation was established (Fig. 1). This flowchart for terminal extubation was drawn with references from available guidelines and recommendations. ${ }^{13-15}$

Our patient did not have his ventilator withdrawn as both the ICU and Palliative Care teams concurred that he would experience significant respiratory distress on extubation as he was supported on high ventilatory settings and was imminently dying.

\section{Post-ICU Palliative Care}

The Palliative Care team plays two important roles after the extubation of terminally ill COVID-19 patients in transition of care and symptom management. We recommend keeping patients who may die within short hours in the ICU and moving those with a relatively longer prognosis (short days) out to single rooms to allow families to be with them (if tested negative subsequently) in their final moments. Patients may develop symptoms like dyspnea, delirium and secretions which the palliative care team can help manage.

\section{Communicating with Families About 'Care After Death' of COVID-19 Patients}

The traditional way of allowing families to keep vigil by the bedside and even touching the dying patient can no longer be allowed due to the highly contagious nature of the coronavirus. Even though $\mathrm{Mr} \mathrm{L}$ had tested negative for COVID-19, his family were only allowed into his room fully gowned in PPE as a precautionary measure.

Families will need advice on specific protocols when their next-of-kin passes on from COVID-19. The healthcare providers and social workers will need to provide relevant information on funeral preparations in adherence to strict infection control rules which in the COVID-19 context included 'double-bagging' of the body, having a 'closed' coffin without a viewing glass, cremation instead of burial and a maximum allowance of 3-days for a memorial service. This information was made known to Mr L's family members and it allowed them time to understand the processes 
Table 1: ICU-Palliative Care Referral Checklist

\begin{tabular}{|c|c|}
\hline INDICATORS & Criteria \\
\hline $\begin{array}{l}\text { POOR CANDIDATE FOR } \\
\text { CRITICAL CARE } \\
\text { Continuing intensive care will not } \\
\text { confer overall benefit }\end{array}$ & $\begin{array}{l}\square \quad \text { Status post cardiac arrest } \\
\square \quad \text { Active stage IV malignancy } \\
\square \quad \text { Advanced dementia (FAST scale stage 7)* } \\
\square \quad \text { End-stage valvular heart disease/ heart failure i.e. New York Heart Association (NYHA) Class III or } \\
\text { IV, EF }<20 \% \text {, repeated admissions, not for surgery } \\
\square \quad \text { End stage renal disease not for renal replacement therapy } \\
\square \quad \text { Clinical Frailty Score } \geq 7\end{array}$ \\
\hline $\begin{array}{l}\text { POOR TREATMENT RESPONSE } \\
\text { The underlying condition is } \\
\text { irreversible or the desired } \\
\text { outcome cannot be achieved }\end{array}$ & $\begin{array}{l}\square \quad \text { Multisystem organ dysfunction syndrome } \geq 2 \text { organ systems } \\
\square \quad \text { Consideration of mechanical ventilator withdrawal after which death is expected }\end{array}$ \\
\hline $\begin{array}{l}\text { EXTREMELY POOR ANTICPATED } \\
\text { QUALITY OF LIFE } \\
\text { There is anticipated poor } \\
\text { neurological recovery or } \\
\text { long-term ventilator dependence }\end{array}$ & $\begin{array}{l}\square \quad \text { Extensive intra-cerebral / subarachnoid haemorrhage with poor neurological prognosis } \\
\square \quad \text { Massive ischaemic stroke with poor neurological recovery } \\
\square \quad \text { Hypoxic ischaemic encephalopathy / anoxic encephalopathy }\end{array}$ \\
\hline $\begin{array}{l}\text { DECISIONAL CONFLICTS/ } \\
\text { SPECIAL CONSIDERATIONS }\end{array}$ & $\begin{array}{l}\square \quad \text { Difficult-to-control physical symptoms despite usual treatment approaches } \\
\square \quad \text { Upon initiation of extracorporeal membrane oxygenation (ECMO) } \\
\square \quad \text { Complex family dynamics impacting decisions about use of life-sustaining treatments } \\
\square \quad \text { Conflicts among staff or between staff and patients / surrogates about prognosis and/or use of life- } \\
\text { sustaining treatments } \\
\square \quad \text { Patients / surrogates wish to explore non-ICU supportive care options such as hospice services }\end{array}$ \\
\hline
\end{tabular}

FAST: Functional Assessment Staging Test; ICU: Intensive Care Unit

*FAST Scale refers to the Functional Assessment Staging Test (FAST) which is a 16-item scale designed to parallel the progressive activity limitations associated with Alzheimer's disease. Stage 7 and beyond suggest unable to ambulate without assistance; unable to dress without assistance; unable to bathe without assistance; intermittent or constant urinary and faecal incontinence; and no consistently meaningful verbal communication (stereotypical phrases only or the ability to speak is limited to six or fewer intelligible words).

and make a decision to honour patient's wish not to have a 'long memorial service'. He was cremated a day after his death.

\section{Bereavement Follow-up}

The pandemic has left many families whose loved ones have passed away from COVID-19 in a terrible state of shock, disbelief and despair. Family members who had spread the virus to the deceased patient can experience significant guilt. This puts them at risk for developing complicated grief and early social worker involvement is recommended.

We called the family a fortnight later to provide bereavement support and they shared their deep sense of loss, sadness and shock. The ICU social workers subsequently continued to follow up with the bereaved family. We recommend post-bereavement phone-calls at least 2-4 weeks after the patient had passed on, after families have had time to settle the patient's immediate affairs and process their grief.

\section{Recommendations on Integrating Palliative Care into a COVID-19 designated ICU}

Based on our experiences, we recommend the following strategies for integrating Palliative Care into a COVID-ICU (Table 2).

\section{Conclusion}

Palliative care has an important role to play in the COVID-19 ICU. It collaborates with the ICU team to incorporate general palliative care principles with early goals of care discussions, regular communication and education of families about treatment expectations resulting in good symptom management at the end of life for COVID-19 patients. The challenges and recommendations that we share are the results of the lessons we had to quickly learn as the pandemic rapidly evolved. We hope the sharing of our experience will help Palliative Care teams in similar situations to better engage and support their ICU teams in their continued efforts to care for the sickest COVID-19 patients. 
Figure 1: Flow chart for Terminal Extubation in COVID-19 Patients

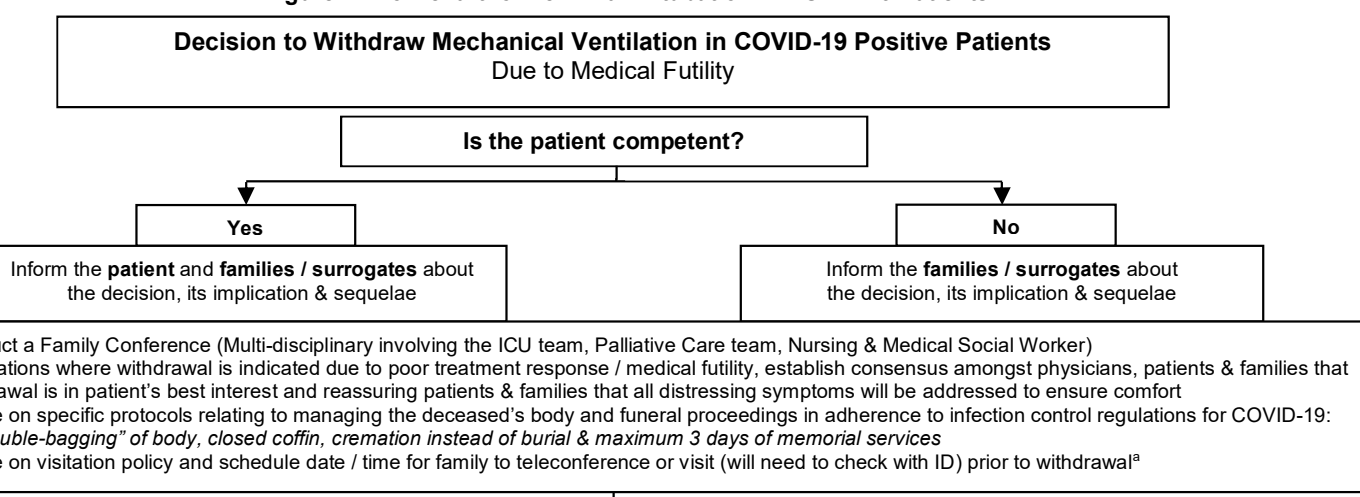

\section{At Least 6-8 Hours Prior to Extubation}

1. Stop enteral feeding \& reduce parental fluids (reduce risk of occurrence of $\quad 5$. If patient is already receiving midazolam for sedation or morphine / respiratory tract secretions) For hypervolemic patient, administer IV frusemide $40-80 \mathrm{mg}$ bolus (reduce bronchopulmonary secretions) (do not give if patient is hypotensive / on inotropic support)

3. IV dexamethasone $8 \mathrm{mg}$ (prevention of post-extubation stridor) Make sure IV / SC access is patent - continue all medications that are palliative in intent (opioids, anxiolytics, anticholinergics) fentanyl for analgesia or respiratory symptoms, and this is considered adequate, continue the infusion
If patient is not sedated or receiving opioids \& is symptomatic, start with parental

parental
a. Morphine / Fentanyl (for pain / dyspnoea)

b. Midazolam (for sedation)

7. Confirm family attendance (through teleconferencing / in-person); Appropriate staff should be present for psycho-emotional support eg medical social worker 8. Explain and prepare family what to expect post-extubation \& estimated prognosis

At Least 30mins Prior to Extubation

1. Allow family to say goodbyes: through teleconferencing / in-person in ICU outside the cubicle (if swab still +) / inside cubicle (if swab is - )

If patient is already receiving midazolam for sedation or morphine / fentanyl for analgesia or respiratory symptoms, and this is considered adequate, continue the infusion. Titrate medications to absence of tachynpnoea and aim for respiratory rate of $12-25 / \mathrm{min}$

3. If breathlessness / tachypnoea is anticipated post extubation :

a. For opioid naive patient: Give STAT IV / SC dose morphine @ 1- $2.5 \mathrm{mg}$ OR fentanyl @ $25 \mathrm{mcg}$

b. For patient on opioid infusion: Give breakthrough dose: $2 x$ the infusion hourly rate then PRN up to every 1-2 hourly

4. If respiratory tract secretions is anticipated post extubation:

a. Give STAT IV / SC hyoscine-N-butylbromide @ 20mg OR glycopyrrolate @ $0.2-0.4 \mathrm{mg}$ then PRN (on top of existing continuous infusion if any)

5. If agitation / restlessness is anticipated:

a. Give STAT IV / SC midazolam @ $1-2.5 \mathrm{mg}$

For prevention of post-extubation stridor if appropriate: IV dexamethasone $8 \mathrm{mg}^{\circ}$

Do suctioning: oral \& ETT; Aspirate NGT

Prepare oxygen mask / nasal cannula at bedside

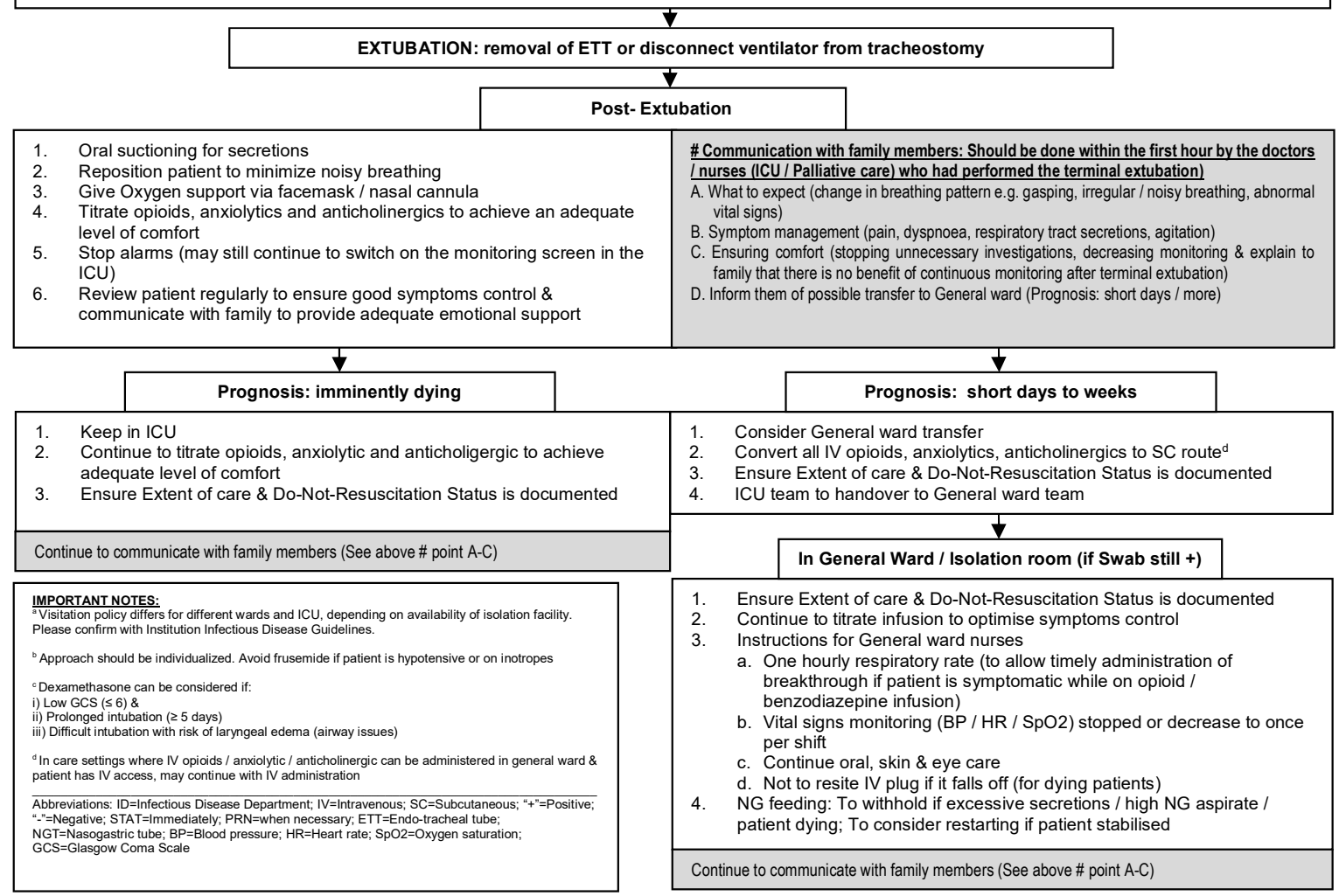


Table 2: Strategies for integrating Palliative Care into a COVID-19 ICU

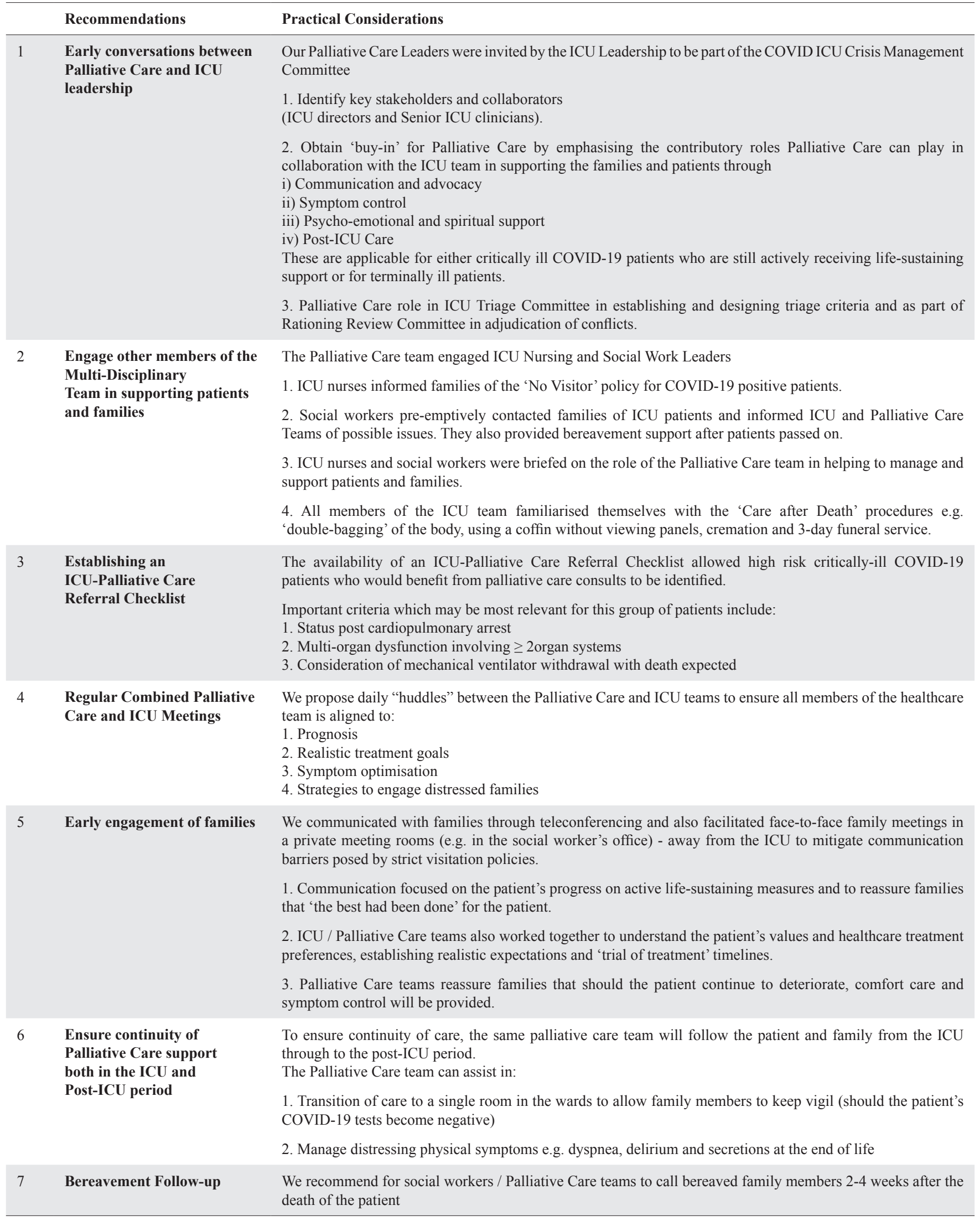




\section{REFERENCES :}

1. Emanuel EJ, Persad G, Upshur R, Thome B, Paker M, Glickman A et al. Fair Allocation of Scarce Medical Resources in the Time of COVID-19. N Engl J Med 2020;382:2049-2055.

2. Ministry of Health, Singapore. Official update of COVID-19 situation in Singapore. Available at: https://www.moh.gov.sg/covid-19/ situation-report. Accessed on 20 June 2020.

3. Hsu LY, Chia PY, Lim JF. The Novel Coronavirus (SARS-CoV-2) Epidemic. Ann Acad Med Singapore 2020;49:105-107.

4. World Health Organization, Coronavirus disease 2019 (COVID-19), situation report 151, 19 June 2020. Available at: https://www.who.int/ docs/default-source/coronaviruse/situation-reports/20200619-covid19-sitrep-151.pdf?sfvrsn=8b23b56e_2. Assessed on 20 June 2020.

5. Wu Z, McGoogan JM. Characteristics of and important lessons from the coronavirus disease 2019 (COVID-19) outbreak in China: summary of a report of 72314 cases from the Chinese Center for Disease Control and Prevention. JAMA 2020; Epud ahead of print

6. Goh CR, Sethi VK. Palliative care in Singapore-good medicine given with compassion. Ann Acad Med Singapore 1994; 23:127-128.

7. Ferguson L, Barham D. Palliative Care Pandemic Pack: a Specialist Palliative Care Service response to planning the COVID-19 pandemic. J Pain Symptom Manage 2020; ;60:e18-e20.

8. Fausto J, Hirano L, Lam D, Mehta A, Mills B, Owens D et al. Creating a Palliative Care Inpatient Response Plan for COVID19The UW Medicine Experience. J Pain Symptom Manage 2020 Jul;60:e21-e26.

9. National Centre for Infectious Diseases (NCID). Available at: https://www.ncid.sg/About-NCID/Pages/default.aspx. Accessed on 20 June 2020.

10. Nelson JE, Bassett R, Boss RD, Brasel KJ, Campbell ML, Cortez TB et al. Improve Palliative Care in the Intensive Care Unit Project: Models for structuring a clinical initiative to enhance palliative care in the intensive care unit: A report from the IPAL-ICU Project (Improving Palliative Care in the ICU). Crit Care Med 2010; 38:1765-1772.
11. Campbell ML, Weissman DE, Nelson JE. Palliative care consultation in the ICU \#253. J Palliat Med 2012;15:715-6.

12. Walker KA, Mayo RL, Camire LM, Kearney CD. Effectiveness of integration of palliative medicine specialist services into the intensive care unit of a community teaching hospital. J Palliat Med 2013;16:1237-1241.

13. Paruk F, Kissoon N, Hartog CS, Feldman C, Hodgson ER, Lipman J, et al. The Durban World Congress Ethics Round Table Conference Report: III. Withdrawing Mechanical ventilationthe approach should be individualized. J Crit Care. 2014; 29:902-907.

14. Kompanje EJ, van der Hoven B, Bakker J. Anticipation of distress after discontinuation of mechanical ventilation in the ICU at the end of life. Intensive Care Med. 2008;34:1593-1599.

15. Bagshaw SM, Delaney A, Farrell C, Drummond J, Brindley PG. Best evidence in critical care medicine. Steroids to prevent postextubation airway obstruction in adult critically ill patients. Can J Anaesth 2008;55:382-385.

Choo Hwee Poi, ${ }^{1}{ }_{M B B S, ~ M R C P},{ }^{*}$

Mervyn YH Koh, ${ }^{1} M B B S, M R C P, F A M S, "$

Han Yee Neo, ${ }^{1}$ MBBS, MRCP, Allyn YM $\underline{\operatorname{Hum}},{ }^{1} M B B C h(B a O)$, MRCP

${ }^{1}$ Palliative Medicine Department, Tan Tock Seng Hospital, Singapore and Palliative Care Centre for Excellence in Research and Education, Singapore * Joint first authors.

Address for Correspondence: Dr Poi Choo Hwee, Department of Palliative Medicine, Tan Tock Seng Hospital, 11 Jalan Tan Tock Seng, Singapore 308433, Singapore

Email:choo_hwee_poi@ttsh.com.sg 